\title{
INTERÉS LEGÍTIMO E INTERÉS PARA RECURRIR EN EL CONTENCIOSO ADMINISTRATIVO AMBIENTAL CHILENO*
}

[Legitimate interest and procedural interest in the Chilean environmental justice system]

\author{
Andrés Bordalí Salamanca** \\ Universidad Austral de Chile
}

\begin{abstract}
RESUMEN
En el presente trabajo se aborda la figura del interés legítimo como posición jurídica legitimante clásica del contencioso administrativo de raíz continental. Se sostiene que esa figura existe en el derecho chileno, junto al derecho subjetivo, como posición jurídica de carácter sustancial de los administrados y está en la base del contencioso de reclamación ambiental. Requisito diferente es un
\end{abstract}

\begin{abstract}
In this paper, I approach the concept of legitimate interest as the classic devise of continental law to determine the legal standing of the plaintiff in the access to the administrative justice system. It is maintained that this concept has been introduced in the Chilean legal system, joining the concept of subjective right, as a legal position of a substantial nature. Legitimate interest is, therefore, at
\end{abstract}

Recibido el 18 de mayo de 2018 y Aprobado el 23 de agosto de 2018

* Este trabajo ha sido realizado en el marco y con el financiamiento del proyecto Fondecyt Regular N. ${ }^{\circ} 1170242$, del que el autor de este trabajo es su investigador responsable. Parte importante del trabajo ha sido realizado con las aportaciones y observaciones del profesor Juan Carlos Ferrada Bórquez, quien es co-investigador del proyecto Fondecyt Regular.

** Abogado, Doctor en Derecho, profesor titular de Derecho Procesal en la Facultad de Ciencias Jurídicas y Sociales de la Universidad Austral de Chile. Dirección postal: Casilla 567, Valdivia. Dirección electrónica: abordali@uach.cl. 
interés procesal para recurrir.

Palabras clave

Derecho Administrativo - Derecho Procesal - Contencioso administrativo - interés legítimo - medio ambiente reclamación - interés procesal. the base of environmental claims. It is argued that the legitimate interest is a requirement different from the procedural interest to bring a case before a Court of law.

\section{Kerwords}

Administrative Law - Procedural Law-Administrative justice - legitimate interest - environment - claim - procedural interest.

\section{INTRODUCCIÓN}

La justicia administrativa ha evolucionado en la mayoría de los países de tradición de derecho continental desde una justicia al acto administrativo a una justicia que tiene por finalidad dar amparo a los derechos e intereses de las personas. De un contencioso objetivo se ha pasado a un contencioso subjetivo.

Pero si se habla de una justicia de carácter subjetivo, se piensa en una que da tutela a los derechos subjetivos de las personas. Éstas tendrán que invocar un derecho subjetivo afectado para que puedan presentar una demanda contra la Administración. Solo quien invoca un derecho subjetivo podrá entenderse legitimado activamente en esa reclamación contra la Administración.

El problema es que no siempre los particulares tienen derechos subjetivos involucrados en conflictos contra la Administración. En muchos casos se trata de situaciones jurídicas subjetivas que no calzan con la figura del derecho subjetivo. Piénsese en el sujeto que no ha ganado un concurso público que fue adjudicado a otra persona que no cumplía con las bases para ganar ese concurso. $\mathrm{O}$ el caso del propietario que quiere construir un edificio de departamentos en un barrio residencial y la autoridad administrativa le niega ilegítimamente el permiso de edificación. O imagínese a un vecino que ve cómo un humedal o laguna cercana donde ese sujeto vive es contaminada y afectada por una empresa cercana.

En esos casos no siempre el sujeto podrá invocar un derecho subjetivo. No tiene un derecho a ganar el concurso público, ni un derecho a construir lo que quiera ni un derecho sobre la naturaleza. Pero sí puede aparecer interesado en todo ello. $\mathrm{Y}$ ese interés se acostumbra a identificarlo como interés legítimo. 
¿Tiene sentido hablar de una posición jurídica subjetiva diferente al derecho subjetivo? ¿Existe algo más que un derecho subjetivo en cabeza de los particulares? Mi respuesta es que sí hay una figura además del derecho subjetivo y ella es el interés legítimo. En materia ambiental cobra especial importancia. Esa figura existe en ordenamientos jurídicos como el chileno y, además, es conveniente que siga existiendo. El análisis que desarrollaré tiene como aspecto central las regulaciones chilenas, pero tiene una proyección teórica y dogmática de interés general.

En las páginas que siguen abordaré la legitimación activa en el contencioso administrativo ambiental chileno (II). Luego, el estudio comprenderá un análisis del interés legítimo como posición jurídica subjetiva legitimante (III), para pasar después a distinguir unas figuras no siempre adecuadamente diferenciadas, como lo son el interés legítimo y el interés para recurrir (IV). Finalmente, terminaré este trabajo con algunas conclusiones (V).

\section{LEGITIMACIÓN ACTIVA EN EL CONTENCIOSO ADMINISTRATIVO AMBIENTAL}

El artículo 18 de la Ley de Tribunales Ambientales chilena, Ley N. ${ }^{\circ}$ 20.600 (en adelante, LTA), en los numerales 1 a 7 , señala quienes están legitimados activamente para interponer las reclamaciones que permite dicha ley.

Si las personas están legitimadas activamente, ello quiere decir que podrán deducir su pretensión válidamente en términos de obligar al juez a tramitar el proceso legal y dictar la sentencia definitiva que se pronuncie sobre la referida pretensión. Dicho de otro modo, significa que quien demanda tiene una conexión jurídica con el objeto litigioso o, si se quiere, con los derechos o intereses sobre los que recaerá la tutela jurisdiccional.

El tema de la legitimación procesal ha sido escasamente tratado por la doctrina chilena, como ya lo hemos señalado en trabajos anteriores ${ }^{1}$. Y la legislación en raras ocasiones la reconoce explícitamente. Una de las pocas leyes que la reconoce es la Ley N. ${ }^{\circ} 19.496$ sobre protección de los derechos de los consumidores (art. 52 a).

La doctrina está dividida sobre cómo considerar la legitimación; si como cuestión procesal o material. He sostenido en otras ocasiones ${ }^{2}$ que es más correcta aquella posición sustentada por un sector de la doctrina que la considera una cuestión procesal ${ }^{3}$. Sin embargo, esta tesis no es aceptada

${ }^{1}$ Vid. Bordalí, Andrés - Hunter, Iván, Contencioso administrativo ambiental (Santiago de Chile, Librotecnia, 2017), pp. 142 ss.

${ }^{2}$ Ídem.

${ }^{3}$ Vid. Fazzalari, Elio, Processo e giurisdizione, en Rivista di Diritto Processuale 48 (1993, II serie), 1, p. 9; Goldschmidt, James, Teoría general del proceso 
por la doctrina y jurisprudencia mayoritarias chilenas, que ven a la legitimación como una cuestión de fondo ${ }^{4}$. Otros autores hablan en vez de legitimación, de la calidad en la acción para que esta última sea acogida ${ }^{5}$.

Tratándose de los procesos ante los tribunales ambientales, tanto el Segundo Tribunal Ambiental como la Corte Suprema consideran a la legitimación como una cuestión de fondo controlada en la sentencia definitiva ${ }^{6}$.

Para estar legitimado activamente, por regla general, se deberá afirmar que se es titular de un derecho subjetivo que necesita tutela jurisdiccional. O bien, que se es titular de un interés legítimo. Esta última categoría es de especial relevancia en el Derecho Administrativo. Son ellas, derecho subjetivo e interés legítimo, las clásicas posiciones jurídicas subjetivas legitimantes en la Justicia Administrativa.

\section{EL INTERÉS LEGÍTIMO COMO POSICIÓN JURÍDICA LEGITIMANTE}

Centrando el análisis en el contencioso administrativo ambiental chileno, hay que señalar que pueden acceder ante los Tribunales Ambientales e incoar el proceso respectivo aquellas personas que sean titulares de un derecho o interés afectado.

Excepcionalmente, se puede comparecer sin tener un derecho ni interés involucrado, es decir como actor popular, en el caso de que se considere que los actos administrativos que dictan los ministerios o servicios públicos para la ejecución o implementación de las normas de calidad, emisión y planes de prevención o descontaminación, infrinjan la ley, las normas y los objetivos de los instrumentos señalados (18 N. 6 LTA).

Salvo esta hipótesis de acción popular, en los otros casos habrá que invocar y demostrar la existencia de un derecho o interés afectado.

Qué tipo de interés deberá concurrir para que se acoja por parte del tribunal de justicia competente la pretensión del demandante es una cuestión que no es clara. Pareciera que se trata de un interés de carácter individual, más restrictivo del que se reconoce en la ley 19.880 sobre

(Barcelona, Labor, 1936), p. 18; Montero, Juan, La legitimación en el proceso civil (intento de aclarar un concepto que resulta más confuso cuando más se escribe de él) (Madrid, Civitas, 1994), p. 37.

${ }^{4}$ Romero, Alejandro, Curso de Derecho Procesal Civil. La acción y la protección de los derechos (Santiago, Editorial Jurídica de Chile, 2006), I, pp. 93-94.

${ }^{5}$ Casarino, Mario, Manual de Derecho Procesal. Derecho Procesal Civil (5a edición, Santiago, Editorial Jurídica de Chile, 1994), III, pp. 114-115.

${ }^{6}$ Sentencia Segundo Tribunal Ambiental de Santiago de 18 de julio de 2014, rol R-16-2013; Sentencia de la Corte Suprema de 22 de abril de 2015, rol 23.000-2014. 
Bases de los Procedimientos Administrativos que rigen los Actos de los Órganos de la Administración del Estado en el artículo 21, que puede ser individual o colectivo.

En efecto, esta disposición señala: "Interesados. Se consideran interesados en el procedimiento administrativo: 1. Quienes lo promuevan como titulares de derechos o intereses individuales o colectivos; 2. Los que, sin haber iniciado el procedimiento, tengan derechos que pueden resultar afectados por la decisión que en el mismo se adopte; 3. Aquellos cuyos intereses, individuales o colectivos, puedan resultar afectados por la resolución y se apersonen en el procedimiento en tanto no haya recaido resolución definitiva".

Alejandro Romero ha señalado que al extender la ley N. ${ }^{\circ} 19.880$ la calidad de interesados a los que actúan instando por la protección de intereses, se estaría aceptando que no solo pueden reclamar los que detenten la titularidad subjetiva de un derecho, sino que también quienes actúan invocando un interés legítimo efectivo, sea éste de carácter individual o colectivo $^{7}$. La ley que regula el procedimiento administrativo en todo caso se refiere a intereses, tanto individuales como colectivos, pero sin que califique a esos intereses como legítimos.

¿Pero es que la ley chilena expresamente habla de invocar derechos o intereses legítimos o de otro tipo para entenderse legitimado activamente?

En un plano jurisdiccional y no ante la Administración, hay que decir que la LTA en ninguna parte habla de invocar derechos o intereses, ni individuales ni colectivos. El artículo 18 LTA se refiere a las distintas hipótesis de legitimados activos, como aquéllos que reclaman porque se les causa un perjuicio; los directamente afectados; los que hubieren presentado sus reclamaciones de conformidad a la ley; el que hubiere solicitado la invalidación, entre otros casos. En ninguna parte se refiere a invocar derechos o intereses, ni individuales ni colectivos. Ni menos hace referencia a intereses legítimos.

Una de las pocas referencias a situaciones jurídicas subjetivas invocables ante los tribunales de justicia es la que hace el artículo 38 inciso $2^{\circ}$ de la Constitución Política de la República (en adelante CPR), en la parte que establece que "cualquier persona que sea lesionada en sus derechos por la Administración del Estado, de sus organismos o de las municipalidades, podrá reclamar ante los tribunales que determine la ley, sin perjuicio de la responsabilidad que pudiere afectar al funcionario que hubiere causado el daño".

Podría entenderse de este modo que cuando la LTA en su artículo 18 hace alusión a las personas que han sufrido un daño o de los directamente afectados, ello sería una proyección en materia legal de la hipótesis consti-

${ }^{7}$ Cfr. Romero, Alejandro, cit. (n. 4), p. 90. 
tucionalmente prevista (art. 38 inciso $2^{\circ} \mathrm{CPR}$ ), de legitimar activamente en el contencioso administrativo a las personas cuando la Administración hubiese violado sus derechos subjetivos. Que una persona sea afectada o perjudicada o que ha sufrido un daño, entre otras expresiones posibles, podría entenderse resumidamente como que se le afectó un derecho subjetivo.

Tenemos de este modo que ante la Administración los comparecientes tendrán que invocar derechos o intereses, individuales o colectivos (art. 21 ley N. ${ }^{\circ}$ 19.880). Y ante los tribunales de justicia, los privados deberán invocar derechos. En ninguna parte se señala que se puedan invocar intereses ante los tribunales, sean ellos legítimos o de otro tipo. Por tanto, se puede poner en duda que la categoría de los intereses calificados como legítimos tenga cabida en el derecho chileno. Ya hemos visto que la Ley 19.880 no habla de intereses legítimos sino solo de intereses.

Cabe por tanto indagar si la categoría de los intereses legítimos tiene reconocimiento normativo, doctrinal y jurisprudencial en Chile. Si la respuesta fuese positiva, se deberá luego determinar en qué consisten.

\section{El interés legitimo en el derecho chileno}

Una primera aclaración sobre el estudio del interés legítimo. Su sede de estudio es la teoría general del derecho, que se ha ocupado también de definir qué es un derecho subjetivo. Más que un tema de la doctrina administrativa o procesal, se trataría de un tema de teoría general del derecho ${ }^{8}$.

Pero la figura del interés legítimo no ha ocupado los estudios de los teóricos del derecho. Ha sido la doctrina administrativista la que principalmente ha estudiado esta categoría. El interés legítimo es una categoría jurídica del derecho administrativo y, agregan algunos, tiene una sede geográfica de estudio muy acotada; es una construcción del todo italiana?

Dicho lo anterior, y concordante con lo anteriormente expresado, la sede natural para intentar reconocer en el derecho chileno a los intereses legítimos, es la dogmática administrativa.

Lo peculiar de esta materia en el derecho chileno, como ya se ha señalado, es que no hay reconocimiento expreso a tales intereses en el derecho administrativo chileno. Sí tiene reconocimiento la figura del interés legítimo en otras normativas que no son de Derecho Administrativo. Así ocurre con el artículo 486 del Código del Trabajo y el artículo $1^{\circ}$ de la Ley sobre Competencia Desleal. Y también ha sido utilizada esta categoría por la doctrina civilista.

${ }^{8}$ Vid. Nigro, Mario, Giustizia amministrativa (6a edición, Bolonia, Il Mulino, 2002), p. 94.

${ }^{9}$ Vid. Travi, Aldo, Lezioni di giustizia amministrativa (12º edición, Turín, Giappichelli, 2016), p. 11. 
En el campo civil un interés legítimo protegido jurisdiccionalmente se da a propósito de terceros que impugnan los efectos de ciertos actos jurídicos fraudulentos, como es el caso de la simulación de un contrato. Así, se ha resuelto que el acreedor valista tiene interés en que se declare la nulidad de un determinado acto que grava los bienes del deudor, ya que con ello puede obtener que un tercero pierda su privilegio pasando los bienes a engrosar el patrimonio en igualdad de condiciones ${ }^{10}$.

Tenemos de este modo que en las áreas del derecho del trabajo, derecho de la competencia y derecho civil chilenos, tanto legislativa como doctrinalmente, la figura del interés legítimo tiene reconocimiento. Sin embargo, en el Derecho Administrativo, que es el área natural para el desarrollo de esta categoría, no tiene reconocimiento legislativo.

De esta manera, es posible concluir que ni la legislación administrativa sustantiva ni procesal chilenas utilizan expresamente la categoría del interés legítimo.

Pero para un sector relevante de la doctrina administrativa chilena sí existe esta categoría. Uno de los primeros autores que vinculó la idea de la legitimación activa con el término de los intereses legítimos fue Eduardo Cordero. Señaló Cordero en su momento que quien alega la nulidad de un acto administrativo debe tener un interés en su eliminación del ordenamiento jurídico, interés que debe ser personal y directo, y además legítimo.

Si bien, explica Cordero, las leyes administrativas no se refieren expresamente a que los recurrentes deben invocar un interés legítimo, sino que se refieren a los "agraviados", "interesados", "quien tenga interés" o "el afectado", entre otras expresiones, se converge "en la idea de interés legítimo, basado en un concepto amplio de lesión, en la medida que si prosperase la pretensión el titular obtendría siempre una utilidad (beneficio) o dejaría de sufrir un perjuicio efectivo de carácter material" ${ }^{11}$.

Para Cordero este interés legítimo no es sino un tipo de derecho subjetivo, y como tal, lo hace entrar en el término derecho a que se refiere el artículo 38 inciso $2^{\circ} \mathrm{CPR}$. Ese término derecho que utilizó el constituyente de 1980 debe ser entendido como "comprensivo de toda situación jurídica reconocida y amparada por el ordenamiento jurídico"12.

Jorge Bermúdez también ha dado una interpretación amplia del artículo 38 inciso $2^{\circ} \mathrm{CPR}$, entendiendo que la expresión "derechos" que se usa ahí, no debe ser entendida en términos estrictos sino que debe ser entendida

\footnotetext{
${ }^{10}$ Cfr. Romero, Alejandro, cit. (n. 4), pp. 90 y 91.

${ }^{11}$ Cordero, Eduardo, La legitimación activa en el proceso contencioso - administrativo, en Ferrada, Juan Carlos (coord.), La justicia administrativa (Santiago, Editorial Jurídica de Chile, 2005), p. 407.

${ }^{12}$ Ibid., p. 414.
} 
como toda posición jurídica digna de ser amparada por una acción, como ocurre con los intereses. Así, por ejemplo, "en las acciones de impugnación de normas la exigencia de perjuicio debe ser entendida como un interés legítimo vulnerado por el decreto supremo..."13.

Bermúdez agrega que cuando la ley se refiere a que el sujeto sufre un perjuicio real, en ese caso hay que suponer que se afecta un derecho subjetivo del privado, mientras que cuando la ley habla del interesado o afectado, bastaría que exista un interés, que debe ser directo ${ }^{14}$.

Juan Carlos Ferrada también sostiene, con matices, que el derecho chileno reconocería la existencia de intereses legítimos. Al respecto, señala que la doctrina civilista ha dado reconocimiento al concepto de interés legítimo, que lo asocia con una idea de ventaja o beneficio. Sin embargo, señala, en el ámbito administrativo, el término interés legítimo no queda restringido a cuestiones patrimoniales, sino que se extiende a todo tipo de bienes de la vida ${ }^{15}$.

En este sentido, Ferrada critica la posición que ha asumido la Corte Suprema chilena, la que ha utilizado el término de interés legítimo, en la nulidad de derecho público, de un modo muy restrictivo, reconduciéndolo en realidad a un verdadero derecho subjetivo.

Arrancando de esta posición crítica de la jurisprudencia de la Corte Suprema, Ferrada no descarta la posibilidad de hacer una interpretación más amplia del vocablo "derecho" que utiliza el artículo 38 CPR. De asumirse una interpretación restrictiva del vocablo "derecho" en el referido precepto constitucional -señala-, ello podría limitar seriamente el ámbito de actuación de la justicia administrativa y la protección de los particulares, restringiendo de ese modo indebidamente las controversias entre los particulares y la Administración solo a controversias de carácter patrimonial ${ }^{16}$.

En definitiva, sin perjuicio de que las leyes administrativas chilenas no utilicen el vocablo "interés legítimo" como posición jurídica subjetiva que se encuentra en la base del sistema de legitimación activa, la doctrina más autorizada entiende que el sistema de legitimación activa en la justicia administrativa chilena, se basa en la afirmación como propios de un derecho subjetivo o bien de un interés legítimo.

${ }^{13}$ Bermúdez, Jorge, La legitimación activa en el contencioso ambiental, en FerraDA, Juan Carlos - Bermúdez, Jorge - Pinilla, Francisco (coords.), La nueva justicia ambiental (Santiago de Chile, Thomson Reuters, 2015), p. 165.

${ }^{14}$ Ibid., p. 169.

${ }^{15}$ Cfr. Ferrada, Juan Carlos, El sistema de justicia administrativa chileno: revisión de la legalidad de actos administrativos o protección de derechos y/o intereses en Revista de Derecho (Valdivia) 25 (2012), 1, p. 122.

${ }^{16}$ Cfr. Ibíd., p. 123. 
Esta posición pasa por darle un carácter más lato al término "derechos" del artículo 38 inciso $2^{\circ} \mathrm{CPR}$, para ampliarlo a toda posición jurídica subjetiva necesitada de tutela jurisdiccional.

Esta tesis de ampliación del término derecho para comprender en él toda situación jurídica reconocida y amparada por el ordenamiento jurídico ha sido utilizada por la Corte Suprema en varios fallos ${ }^{17}$.

En este sentido, con esta doctrina administrativa, se puede decir que desde el artículo 38 inciso $2^{\circ} \mathrm{CPR}$, el sistema de justicia administrativa chileno se basa en un sistema subjetivista, que busca dar protección a los individuos frente a actos ilegítimos o inválidos de la Administración del Estado. Esto viene a decir que toda persona que sufre un daño o perjuicio o se lo prive de una ventaja, como consecuencia directa de un acto ilegítimo o inválido de la Administración del Estado, estará legitimado para presentar una reclamación contra esa Administración ante los tribunales de justicia que indique la ley. Y ese daño causado o privación de ventaja, podrán ser expresión de la titularidad de un derecho subjetivo o de un interés legítimo afectado.

\section{2. ¿Qué cosa es eso llamado interés legítimo?}

El concepto de interés legítimo está muy ligado a la evolución del derecho administrativo continental, francés en un primer momento, pero sobre todo italiano. Es en Italia donde el término ha sido reconocido en la doctrina y jurisprudencia y, desde 1947, en la Constitución. También otras constituciones lo han incorporado, como la española de 1978.

El debate en Italia sobre si tiene sentido hablar de una posición jurídica subjetiva diversa al derecho subjetivo, en este caso, el interés legítimo, ha sido arduo. Y lo mismo ha ocurrido respecto a la determinación de su contenido. Y esa discusión se ha mantenido durante todo el siglo XX y continúa hasta el día de hoy en pleno siglo XXI.

Con base a esa discusión italiana intentaré reconstruir el sentido del término interés legítimo.

En el derecho italiano las controversias contra la Administración del Estado referidas a determinar la existencia de una obligación del ente estatal respecto a un ciudadano o bien, a condenar a esa Administración al pago de una suma de dinero, suponían un derecho subjetivo en cabeza del reclamante. Por el contrario, si la controversia suponía una pretensión

${ }^{17}$ Vid. Sentencias de la Corte Suprema recaídas en los casos "Agrícola Forestal Reñihue Ltda. Con Cubillos Casanova, Juan Carlos y Fisco de Chile”, rol № 3011 -2006; "Sociedad Visal Ltda. Con Empresa Portuaria de Arica”, rol N 1428 - 2007 y "Federación Aérea de Chile con Fisco de Chile", rol N 598-2010. 
constitutiva de anulación del acto administrativo, como fundamento de ella debía haber un interés legítimo.

¿Por qué esta diferenciación? Algunos han señalado que en las leyes italianas de fines del siglo XIX que comienzan a diseñar el modelo de justicia administrativa de este país, se debe partir de una premisa muy elemental: si las leyes administrativas atribuían poderes a la Administración, entonces esa atribución excluía la atribución contemporánea de derechos en cabeza de los administrados. Por otro lado, si las leyes civiles y políticas atribuían derechos subjetivos a los ciudadanos, entonces la Administración carecía de poderes ${ }^{18}$. Se trata de una total incompatibilidad entre poderes administrativos y derechos subjetivos.

Obviamente, en este cuadro el ciudadano quedaba en muchos casos completamente desprotegido frente al poder de la Administración.

Las leyes de 1889 y 1890 crean un sistema dual de justicia. Si el ciudadano invocaba un derecho subjetivo respecto a la Administración, conocía el juez ordinario (civil) y si se invocaba un interés legítimo, conocía un juez especial administrativo. Digo juez especial porque ese aparecía inserto dentro de una estructura administrativa o al menos cercana a la Administración.

Scoca sostiene que este cuadro doblemente dual de jurisdicciones y de situaciones jurídicas subjetivas invocadas ante cada una de ellas, no fue deseada ni perseguida conscientemente ${ }^{19}$. En estricto rigor, ante ese juez especial administrativo el ciudadano no ostentaba siquiera una posición jurídica subjetiva, sino que se trataba de una justicia de carácter objetivo, donde el interés que tiene que invocar el ciudadano solo es un motivo $\mathrm{u}$ ocasión para que se realice un examen de los actos de la Administración.

Precisando un poco más la situación, hay que señalar que no es que el ciudadano en Italia a fines del siglo XIX careciera de toda tutela jurisdiccional. En sus relaciones contractuales con la Administración por supuesto que obtenía tutela por parte del juez ordinario. Así en los negocios entre Administración y ciudadanos referidos a la adquisición o arriendo de bienes, cualquier controversia entre ellos era competencia del juez ordinario.

El problema surgía respecto de aquellos actos unilaterales de la Administración, como concesiones, autorizaciones, órdenes y prohibiciones, que afectaban a los ciudadanos, es decir lo que algunos han llamado actos de imperio. Esos actos quedaban a fines del siglo XIX fuera del control judicial. Solo la Administración, a través del Consejo de Estado, podía

${ }^{18}$ Vid. Scoca, Franco Gaetano, La genesi del sistema delle tutele nei confronti della pubblica amministrazione, en ScocA, F. G. (ed.), Giustizia amministrativa (6 $6^{\mathrm{a}}$ edición, Turín, Giappichelli, 2014), pp. 7 ss.

${ }^{19}$ Cfr. Ibid., p. 11. 
revisar esa situación de los ciudadanos afectados. Se configura así, para algunos, un privilegio para la Administración donde los intereses privados de los ciudadanos aparecían subordinados al interés público gestionado por la Administración ${ }^{20}$.

En esa idea de que los individuos no tenían derechos subjetivos frente a actos unilaterales de la Administración, sino solo un interés protegido refleja y ocasionalmente, en la medida que coincidía con el interés público, subyace a juicio de un sector de la doctrina una ideología que asignaba al interés del individuo una posición absolutamente subordinada a la Administración y sus intereses ${ }^{21}$.

Hay que agregar que la figura del interés legítimo surge en Italia en un contexto de evidente autoritarismo, entendiendo por tal para estos efectos como una situación de ciertos privilegios para la Administración y una subordinación de los ciudadanos frente a los poderes públicos.

Sin embargo, uno podría entender que esta figura tan vinculada a sistemas políticos no liberales, como se ha dicho, sería dejada en el olvido en el cuadro constitucional creado luego de la Segunda Guerra Mundial. Sin embargo, y por el contrario, la Constitución de 1947 es el primer texto normativo que de manera expresa se refiere al término interés legítimo, pues antes solo había tenido reconocimiento doctrinal y jurisprudencial ${ }^{22}$.

Una de las razones que se dan para que los constituyentes de 1947 mantuvieran la denominación del interés legítimo, pese a que la figura tenía una larga data de raigambre autoritaria, fue que había sido largamente utilizada por el Consejo de Estado italiano y este órgano gozaba entre los constituyentes de mucho prestigio. Además, el órgano había observado bastante independencia respecto del régimen fascista. De este modo, dichos constituyentes reconocieron la figura del interés legítimo y el sistema dual de jurisdicción antes existente ${ }^{23}$.

Que el interés legítimo haya recibido expreso reconocimiento en la Constitución italiana de 1947 tiene algunas consecuencias. La primera ya se adelantaba. No puede asociarse necesariamente esta figura a regímenes autoritarios o sistemas donde los individuos no pueden acceder a la judicatura a defenderse frente a una Administración abusiva. Los individuos tienen derecho a obtener tutela jurisdiccional frente a la Administración, ya sea que se los afecte en sus derechos subjetivos o intereses legítimos

${ }^{20}$ Vid. Porro, Angelo, Le origini del sistema di giustizia amministrativa in Italia. Riflessioni e documenti (Milán, Librerie Cuem, 1995), p. 18.

${ }^{21}$ Vid. Nigro, Mario, cit. (n. 8), p. 100.

${ }^{22}$ Vid. Ricci, Gian Franco, Principi di diritto processuale generale (3 $3^{\text {a }}$ edición, Turín, Giappichelli, 2001), p. 53.

${ }^{23}$ Vid. Scoca, Franco Gaetano, cit. (n. 18), pp. 20-21. 
Por otro lado, se dice que el reconocimiento del interés legítimo en la Constitución, hace descartar aquellas posiciones que ven a esta figura con un significado solo procesal.

Las concepciones meramente procesales del interés legítimo señalan que él comporta para el ciudadano un puro poder de reacción procesal para la tutela del interés lesionado por la autoridad administrativa. Antes del acto administrativo ilegítimo no hay nada en cabeza del ciudadano. Una vez que nace ese acto surge el interés legítimo para pedir la anulación del acto $^{24}$. El interés legítimo es un mero poder de reacción en los términos de una providencia ilegítima de la Administración ${ }^{25}$.

De este modo, el reconocimiento constitucional en Italia (arts. 24 y 113) permitió afirmar la concepción sustancial del interés legítimo ${ }^{26}$. La Constitución italiana reconoce junto al derecho subjetivo como posición jurídica sustancial, al interés legítimo ${ }^{27}$. De esta manera, la doctrina italiana está conteste hoy en día en que el interés legítimo es una posición jurídica sustancial.

Y lo mismo ha sostenido un sector relevante de la doctrina administrativa chilena. El interés legítimo en Chile tiene una naturaleza sustancial y no procesal ${ }^{28}$.

\section{Interés legitimo y derecho subjetivo}

Reconocida esa naturaleza sustancial, la doctrina ha discutido si el interés legítimo es una posición jurídica diferente o autónoma respecto al derecho subjetivo, o bien, si pueden entenderse bajo una misma figura.

Algunos sostienen entonces que las posiciones jurídicas subjetivas que pueden invocar los privados frente a la Administración del Estado son un derecho subjetivo o un interés legítimo. Otros señalan que solo se deben invocar derechos subjetivos, pues no hay nada más allá en cabeza de los administrados.

Luigi Ferrajoli es uno de los autores que le niega entidad propia a los intereses legítimos. Si la Administración tiene el deber, señala Ferrajoli, de recibir y valorar una demanda mía, por ejemplo de admisión a un concurso, yo tengo el derecho que esta demanda sea recibida y valorada.

${ }^{24}$ Vid. Nigro, Mario. cit. (n. 8), P. 97.

${ }^{25}$ Vid. Zito, Alberto, L'ambito della giurisdizione del giudice amministrativo, en Scoca, Franco Gaetano (ed.), Giustizia amministrativa (6a edición, Turín, Giappichelli, 2014), p. 80.

${ }^{26}$ Vid. Scoca, Franco Gaetano, cit. (n. 18), p. 21; Travi, Aldo, cit. (n. 9), p. 72.

${ }^{27}$ Zito, Alberto, cit. (n. 25), p. 80.

${ }^{28}$ Cordero, Eduardo, cit. (n. 11), p. 407; Ferrada, Juan Carlos, cit. (n. 15), p. 122 . 
No tiene por tanto espacio la figura espúrea a su juicio de los "intereses legítimos", a los cuales los derechos subjetivos serían degradados por obra de los actos administrativos. Esta categoría fue por lo demás construida en el siglo XIX por la doctrina y la jurisprudencia italianas precisamente porque ellas no estaban dispuestas a admitir la existencia de derechos de los ciudadanos frente al Estado. La separación entre derechos subjetivos e intereses legítimos y dos tipos diversos de jurisdicciones, son dos consecuencias insostenibles -sostiene el autor italiano-, una vez que se reconoce el nexo que siempre subsiste entre "obligaciones de" y "derechos a" prestaciones y entre "prohibiciones de" y "derechos a no" lesiones ${ }^{29}$.

En otras ocasiones se ha señalado que entre un derecho subjetivo y un interés legítimo no hay diferencias ontológicas que justifiquen tratamientos diferenciados ${ }^{30}$. Y vista la evolución de la jurisprudencia italiana, donde los intereses legítimos reciben una tutela reparadora íntegra, al menos desde el año 1999, se señala por algunos que se ha elevado al rango de derechos las situaciones tradicionalmente definidas como interés legítimo, que asegura a quien sea su titular la posibilidad de conseguir el bien de la vida poniendo en cabeza de la Administración un vínculo jurídico. Algunos proponen denominar a los derechos subjetivos e intereses legítimos que se invocan ante la Administración, como "derechos administrativos", en espera de una definición más apropiada ${ }^{31}$.

Otros autores sostienen que no se observa diferencia alguna entre el derecho subjetivo y el interés legítimo. Y si desaparece la denominación interés legítimo no desaparece por ello el Derecho Administrativo. El término interés legítimo -se dice- es superfluo, no aporta nada, pues no cumple ninguna función práctica. Se ha convertido, se dice, en una metáfora del Derecho Administrativo con una importancia solo nominal ${ }^{32}$.

Algo similar ha intentado en Chile Eduardo Cordero, quien ha propuesto reunificar la posición jurídica del administrado en el concepto de lesión. Sostiene Cordero que "por esta vía se superan los problemas que conlleva la distinción entre derecho subjetivo e interés, por una parte, así

${ }^{29}$ Cfr. Ferrajoli, Luigi, Principia iuris. Teoria del diritto e della democrazia,. 1. Teoria del diritto (Roma, Laterza, 2007), p. 652.

${ }^{30} \mathrm{Vid}$. Verde, Giovanni, Ma che cos è questa giustizia amministrativa, en Diritto Processuale Amministrativo 11 (1993), 4, p. 620.

${ }^{31} \mathrm{Vid}$. Iannotta, Lucio, L'interesse legittimo nell'ordinamento republicano, en Diritto Processuale Amministrativo 25 (2007), 4, p. 950.

${ }^{32}$ Vid. Mazzamuto, Marco, A cosa serve l'interesse legittimo? en Diritto Processuale Amministrativo 30 (2012), p. 77. 
como la determinación de la naturaleza jurídica de este último"33. El interés legítimo para este autor vendría a ser un tipo de derecho subjetivo ${ }^{34}$.

Sin embargo, la mayoría de la doctrina italiana sostiene que se trata de situaciones jurídicas diferentes. En el caso italiano la principal razón para sostener esto es de base normativa. La Constitución italiana en sus artículos 24 y 113 reconoce ambas figuras.

Los intentos de homologar ambas situaciones en el caso italiano, a una sola posición sustancial, viene a ser, se dice, un forzamiento al límite de la interpretación constitucional ${ }^{35}$.

Pero el hecho de que el legislador, constitucional u ordinario, reconozca expresamente a la figura del interés legítimo junto al derecho subjetivo, como posiciones jurídicas legitimantes de los privados, no debe ser tenida como la única ni menos la principal razón para entender la validez de la figura.

La validez del interés legítimo debe buscarse en que hay ámbitos de la vida de las personas que pueden ser afectados por decisiones de la Administración del Estado y esos ámbitos no siempre caben en la figura del derecho subjetivo. El derecho subjetivo viene a ser un espacio de garantía para el ciudadano más estrecho que el interés legítimo.

En este sentido, el interés legítimo puede ser entendido como un ensanchamiento de las facultades del individuo respecto a su vida en sociedad y en sus relaciones con la Administración del Estado. Dicho de otro modo, el interés legítimo, sin perjuicio de que tiene sus orígenes en momentos y sistemas políticos de signo autoritario, con el tiempo se ha mostrado todo lo contrario, pues ha permitido a las personas ampliar sus espacios de libertad.

En esta idea de reconocerle todo su potencial al interés legítimo, como posición jurídica sustancial que convive junto al derecho subjetivo, a veces se lo vincula con una justicia administrativa de tipo subjetivista y también con un proceso de democratización de la Administración Pública ${ }^{36}$.

De este modo, y desde una valoración positiva, sostendré que el interés legítimo es una categoría diferente al derecho subjetivo. Se trata de un interés referido a la esfera de libertad y bienestar de las personas y que amplía el espacio de tutela que tradicionalmente ha proporcionado el derecho subjetivo.

${ }^{33}$ Cordero, Eduardo, cit, (n. 11), p. 404.

${ }^{34}$ Ibid., p. 408.

${ }^{35}$ Vid. Benvenuti, Luigi, Diritto e amministrazione. Itinerari di storia del pensiero (Turín, Giappichelli, 2011), p. 174.

${ }^{36}$ Spampinato, Biagio, $L$ 'interesse a ricorrere nel processo amministrativo (Milán, Giuffrè, 2004), p. 138. 
El interés legítimo supone un modo de participación más activo de parte de los ciudadanos en las decisiones de la Administración Pública, aspecto que no siempre puede encajar en un derecho subjetivo.

En lo que sigue intentaré determinar las principales características del interés legítimo.

\section{Contenido del interés legitimo}

Hay varias cuestiones referidas al interés legítimo que se deben dilucidar. Una de ellas dice relación si el interés legítimo existe con prescindencia de un acto administrativo o no.

Tradicionalmente se ha entendido que el interés legítimo nace con el acto administrativo y que existe solo con el fin de pretender anular dicho acto. Antes del procedimiento administrativo el individuo tendría una simple expectativa, que con el procedimiento administrativo se transformaría un una situación jurídica sustancial. Piénsese, se dice, en un concurso público. Todos los que cumplen con los requisitos pueden postularse y aspirar al puesto (expectativa), pero solo uno o algunos podrán ser en definitiva los vencedores. Los perdedores o excluidos del concurso tendrán el poder de controlar si el procedimiento que no los favoreció es legítimo o no. Y ahí nace en cabeza de esos reclamantes un interés legítimo, para declarar nulo el concurso por existir un vicio que los perjudica. De una mera expectativa que no tiene reconocimiento jurídico, se pasa a una situación jurídica sustancial con ocasión del acto administrativo ${ }^{37}$.

Esta posición que ve nacer al interés legítimo solo con el acto administrativo, no parece exacta. Y no lo es, porque supondría limitar severamente este espacio de los individuos referidos a bienes de la vida que tienen reconocimiento por el ordenamiento jurídico. Si el ordenamiento reconoce ese espacio de libertad de los individuos, se le está en algún sentido negando su naturaleza sustancial cada vez que lo condiciona a que se dicte un acto administrativo para que adquiera plena vida.

De este modo, para determinar si un individuo tiene un interés legítimo, no se debe atender al criterio que exista un acto administrativo, sino que se debe recurrir al sistema normativo y ver si ahí tiene cabida. Se tiene por tanto un interés legítimo cuando el ordenamiento jurídico confiere una particular relevancia jurídica a un interés material ${ }^{38}$. Obviamente, está estrechamente vinculado a la acción administrativa.

Como posición jurídica sustancial, el interés legítimo nace al menos con el inicio del procedimiento administrativo que conduce al acto terminal.

${ }^{37}$ Vid. Ricci, Gian Franco, cit. (n. 22), p. 53.

${ }^{38}$ Vid. Nigro, Mario, cit. (n. 8), p. 113. 
Y quizás, como sostiene alguna doctrina ${ }^{39}$, nace antes del procedimiento administrativo. La tesis que sostiene que el interés legítimo nace con independencia del acto administrativo, señala que se trata de un interés material consistente en un bien de la vida y como tal, no puede restringirse este bien de la vida con un interés a la legitimidad de la actividad administrativa ${ }^{40}$.

La legitimidad de la actividad administrativa no es el bien de la vida que está en el seno del interés legítimo. Y no lo puede ser porque ese interés material en que consiste el interés legítimo tiene que referirse a un bien de la vida, como una situación de ventaja o un sustrato económico ${ }^{41}$.

Si se lo vincula con el ejercicio del poder administrativo, en ningún caso queda restringido a impugnar el acto administrativo terminal, sino que opera desde antes y después de la emanación del acto administrativo. El interés legítimo comporta el poder de provocar el ejercicio de la potestad administrativa, de participar en el procedimiento administrativo, de deducir recursos administrativos contra el acto administrativo, así como los recursos jurisdiccionales que contemple la ley ${ }^{42}$.

Asumiendo la tesis que interés legítimo y derecho subjetivo no son situaciones jurídicas homologables ¡cómo distinguir a un interés legítimo de un derecho subjetivo? La respuesta no es para nada fácil y la doctrina italiana ha ensayado varias respuestas, las que, se puede decir, no tienen unánime aceptación.

Aldo Travi, uno de los autores que últimamente más se ha extendido sobre el estudio del interés legítimo, esquematiza y analiza críticamente algunas respuestas a la pregunta recientemente formulada. De este modo, distingue entre la tesis de las normas de acción y de relación; la de la actividad vinculada a un interés público o a intereses privados; la que distingue entre mal ejercicio del poder y la carencia de poder y la de los intereses constitucionalmente tutelados, entre las principales ${ }^{43}$.

Las normas de acción disciplinan el poder y el ejercicio del poder administrativo y las normas de relación regulan una relación intersubjetiva y sus efectos ${ }^{44}$. Otras veces se dice que con las normas de acción se regula y tutela por vía directa el interés público, mientras que en las normas de relación se regula y tutela en vía principal el interés del particular ${ }^{45}$. En las normas de acción puede observase un interés legítimo del particular

\footnotetext{
${ }^{39}$ Vid. Travi, Aldo, cit. (n. 9), p. 72.

${ }^{40}$ Vid. Ibid., p. 73.

${ }^{41}$ Vid. Ibid., p. 72; ZITo, Alberto, cit. (n. 25), p. 87.

${ }^{42}$ Vid. Nigro, Mario, cit. (n. 8), p. 102.

${ }^{43}$ Cfr. Travi, Aldo, cit. (n. 9), pp. 62 ss.

${ }^{44}$ Vid. Ibid., p. 61.

${ }^{45}$ Vid. Zito, Alberto, cit. (n. 25), p. 76.
} 
mientras que en las normas de relación, un derecho subjetivo. Esta teoría ha sido muy criticada y la jurisprudencia no le da validez actualmente. En las normas de acción puede haber intereses legítimos o derechos subjetivos ${ }^{46}$.

Otras veces se acostumbra a distinguir según cómo es la actividad de la Administración, si es una actividad vinculada o es discrecional. Frente a una actividad vinculada, el particular puede esgrimir derechos subjetivos, mientras que frente a una actividad discrecional de la Administración, el particular solo puede esgrimir intereses legítimos. Travi distingue en la actividad vinculada si se atribuye en el interés del ciudadano o en el interés de la Administración. En el primer caso aparecerían derechos subjetivos y en el segundo intereses legítimos ${ }^{47}$. Tampoco cuenta esta tesis con el apoyo de la doctrina y la jurisprudencia ${ }^{48}$.

En algún momento la Corte de Casación italiana ${ }^{49}$ sostuvo la tesis que cuando se impugnaba un acto por mal ejercicio del poder, en la base de la reclamación había un interés legítimo, mientras que si se impugnaba por inexistencia de poder, el sujeto invocaba un derecho subjetivo. En el caso de mal ejercicio del poder, casos de incompetencia del órgano o exceso de poder, por ejemplo, mientras no sea anulado el acto, éste es válido y por tanto se está en presencia de un poder de la Administración y ahí aparecen intereses legítimos, no derechos subjetivos. Mientras que en el caso de actos donde no hay un poder ejercido, como los casos de incompetencia absoluta del órgano, el acto no es válido y como tal la Administración no ejerció ningún poder, por lo tanto el sujeto conserva los derechos subjetivos intactos. Entre otras críticas a esta teoría, se ha señalado que los casos de carencia de poder son bastante marginales, por lo que no da luces suficientes a la distinción entre ambas categorías ${ }^{50}$.

Finalmente, a veces se habla de derechos constitucionalmente tutelados o derechos insuprimibles o perfectos. Son aquellas situaciones en que tanto la Constitución como la jurisprudencia les dan el máximo reconocimiento y tutela. Piénsese en los derechos de la personalidad, como el derecho a la integridad personal, derecho al nombre, el derecho a la salud o el derecho a la salubridad del ambiente. En estas situaciones solo puede hablarse de derechos subjetivos y no de intereses legítimos. En estos casos, la relevancia de la posición subjetiva implicará una especie de rigidez originaria que

\footnotetext{
${ }^{46}$ Vid. Travi, Aldo, cit. (n. 9), p. 62.

${ }^{47}$ Cfr. Ibíd.

${ }^{48}$ Cfr. Ibid.

${ }^{49}$ Sentencia de la Casación, de fecha 4 de julio de 1949, N. ${ }^{\circ} 1657$.

${ }^{50}$ Vid. Travi, Aldo, cit. (n. 9), p. 63.
} 
impide toda compresión por parte de la Administración. Nunca habrá respecto de ellas intereses legítimos, sino que solo derechos subjetivos ${ }^{51}$.

Pero en algunos casos, derechos que tienen reconocimiento constitucional, ceden total o parcialmente respecto al poder de la Administración, como sucede con el derecho de propiedad y el derecho a la empresa. Por lo tanto, el estatus de una posición jurídica constitucionalmente tutelada tampoco permite distinguir adecuadamente entre intereses legítimos y derechos subjetivos.

¿Qué cosas claras se pueden decir del interés legítimo? Hoy en día hay consenso en la doctrina que se trata de una posición jurídica de carácter sustancial y no se trata de un mero poder de reacción procesal. Existe también cierto acuerdo para entender que se trata de una figura de igual relevancia que el derecho subjetivo. Ninguna es más que la otra ${ }^{52}$.

Por otra parte, parecen razonables los criterios mínimos que propone Travi para identificar al interés legítimo. Ellos son los de diferenciación y de cualificación. No se trata de un interés general o popular, sino que se trata de una posición subjetiva atribuida a uno o más sujetos concretos. Por ello se habla de diferenciación. Por otra parte, atendiendo al criterio de la cualificación, ese interés debe recibir un reconocimiento por el ordenamiento jurídico. No es un interés social o económico, sino que debe recibir un reconocimiento directo o indirecto por uno o más preceptos jurídicos ${ }^{53}$.

Entre las distintas maneras de concebir al interés legítimo, se pueden destacar aquellas que lo conciben como una figura activa de uno o más sujetos, que se caracteriza por un conjunto de prerrogativas dirigidas a influir sobre la acción administrativa. Y en la base de esa figura activa, existe una posición jurídica sustancial referida a un bien de la vida ${ }^{54}$.

A diferencia del derecho subjetivo, en el interés legítimo ese bien de la vida que está en su base no se realiza de manera autónoma por el titular del mismo, sino que se modela en relación al poder de la Administración del Estado ${ }^{55}$.

Otra diferencia con el derecho subjetivo estriba que en el interés legítimo es una posición jurídica subjetiva activa que se pone de frente a otra situación también activa, que es la potestad administrativa. En cambio con el derecho subjetivo como posición jurídica subjetiva activa, frente a él

\footnotetext{
${ }^{51}$ Ibid., p. 65.

${ }^{52}$ Vid. Nigro, Mario, cit. (n. 8), p. 103.

${ }^{53}$ Vid. Travi, Aldo, cit. (n. 9), p. 67.

${ }^{54}$ Ibid., pp. 72 ss.

${ }^{55}$ Ibid.
} 
no puede haber otra posición activa, sino que derechamente obligaciones o deberes ${ }^{56}$.

De acuerdo a los efectos que produce el actuar de la Administración sobre las posiciones jurídicas subjetivas modeladas como interés legítimo, la doctrina y jurisprudencia italianas suelen distinguir entre intereses legítimos opositivos y aquellos pretensivos. En el caso que el actuar administrativo imponga sacrificios o limitaciones al interés material del particular, se habla de intereses legítimos opositivos, puesto que el individuo buscará detener el actuar de la Administración. Si el actuar de la Administración trae una ventaja o beneficio para el individuo, el individuo querrá que se desarrollen al máximo esos poderes de la Administración y se habla, en ese caso, de un interés legítimo pretensivo ${ }^{57}$.

Una definición dentro de las posibles del interés legítimo es la que propone Nigro, que lo identifica como una posición de ventaja reconocida a un sujeto por el ordenamiento jurídico, en relación a una utilidad objeto de poder administrativo y que consiste en la atribución al mismo sujeto de poderes dispuestos a influir sobre el correcto ejercicio del poder, de modo tal de hacer posible la pretensión referida a esa utilidad ${ }^{58}$.

En otros casos se define al interés legítimo como la posición de ventaja concedida a un sujeto por el ordenamiento jurídico referido a un bien de la vida objeto de poder administrativo ${ }^{59}$. Otros precisan que ese poder de la Administración solo es aquél discrecional ${ }^{60}$, lo que es negado por otra doctrina, que señala que los derechos subjetivos también pueden ponerse de frente al poder discrecional de la Administración ${ }^{61}$.

Obviamente aquí se está hablando del interés legítimo que se observa en el campo del derecho público, que se lo vincula necesariamente a la actividad de la Administración del Estado. Pero también en el derecho privado se habla a veces de situaciones jurídicas subjetivas asimilables a la del interés legítimo ${ }^{62}$.

Veamos algunos casos de Derecho Administrativo donde podría observarse la presencia de intereses legítimos. El caso típico es el del proponente que participa en una licitación pública de la cual ha sido excluido al margen de las bases de licitación. El excluido no tiene una situación jurídica tal que

${ }^{56}$ Vid. Ziтo, Alberto, cit. (n. 25), p. 82.

${ }^{57}$ Ibid.

${ }^{58}$ Vid. Nigro, Mario, cit. (n. 8), p. 103.

${ }^{59}$ Vid. Zito, Alberto, cit. (n. 25), p. 85.

${ }^{60} \mathrm{Vid}$. Spampinato, Biagio, cit. (n. 36), p. 88.

${ }^{61}$ Vid. Mazzamuto, Marco, cit. (n. 32), p. 66.

${ }^{62}$ Vid. Nivarra, Luca - Ricciuto, Vincenzo - Sconamiglio, Claudio, Istituzioni di Diritto Privato (Turín, Giappichelli, 2016), p. 60. 
pueda exigir que se le adjudique la licitación. Eso sería propio de un derecho subjetivo y esa figura no es posible de configurarse en una operación administrativa en que hay distintos participantes privados. Pero sí tiene un interés a que si la adjudicación de la licitación se ha realizado de un modo ilegal o ilegítimo, pueda pedir desde ya la anulación de la adjudicación y que se realice nuevamente la adjudicación, esta vez de manera legítima, para sí volver a tener intacta la posibilidad o chance de adjudicársela.

Este ejemplo se aplica en condiciones muy similares para postular vía concurso público a un cargo en la Administración del Estado.

En el derecho urbanístico también pueden darse situaciones referidas a intereses legítimos. Quien pide a la autoridad un permiso para construir en un terreno de su propiedad, ostenta un interés legítimo a construir. Pero no tiene un derecho a construir que pueda exigirlo a la autoridad administrativa. Tiene en ese caso un interés legítimo, que se verá afectado si la autoridad administrativa lo deniega de un modo ilegal o ilegítimo.

En el ius aedificandi, se habría producido una especie de retroceso del individuo frente al poder administrativo. En un comienzo, dentro de las facultades del dominio, el propietario tenía un derecho subjetivo, absoluto, a construir en su propiedad. Con el tiempo, se lo pasó a considerar como un derecho más relativizado, pues aparece condicionado a una autorización administrativa. Y la jurisprudencia italiana actualmente lo concibe como un interés legítimo ${ }^{63}$.

Y luego están las situaciones referidas a temas ambientales, donde también suele observarse la presencia de intereses legítimos. Y la doctrina italiana constata una posición muy laxa de la jurisprudencia en orden a entender que los particulares están legitimados para interponer reclamaciones en materia ambiental, no exigiéndose muchas veces una contigüidad geográfica entre el individuo y un ecosistema afectado. Por otra parte, esa misma jurisprudencia ha entendido que esas personas tienen un interés legítimo en la protección ambiental, aun cuando no pueda entenderse que esos individuos hayan sufrido algún daño subjetivizado ${ }^{64}$.

En relación al punto anterior, hay que mencionar que existe una construcción doctrinal que permite distinguir entre derechos subjetivos e intereses legítimos ambientales, atendiendo al factor geográfico. Así, cuando se trata del ambiente inmediato o próximo de un sujeto, puede hablarse perfectamente de la vulneración de un derecho subjetivo del sujeto afectado, porque en esas condiciones se afecta al sujeto directamente en su

${ }^{63}$ Vid. Nigro, Mario, cit. (n. 8), p. 107.

${ }^{64}$ Vid. Lombardi, Roberta, Le azioni collettive, en Scoca, Franco Gaetano (ed.), Giustizia Amministrativa (6a edición, Turín, Giappichelli, 2014), pp. 216-217. 
relación con el medio ambiente y los bienes jurídicos de la vida, salud o calidad de vida. En cambio, un medio ambiente mediato o remoto puede ser entendido como aquél espacio que si bien no está al alcance de un disfrute directo para el sujeto, puede ser igualmente influyente y configurador del estado de propiedades del ambiente inmediato futuro para ese sujeto ${ }^{65}$.

Así, la conservación de un bosque podría quedar comprendida dentro del objeto de un interés legítimo a vivir en un medio ambiente adecuado, mientras que la contaminación del aire que respira ese mismo sujeto en su casa, espacios públicos o lugar de trabajo, puede quedar comprendida dentro de la figura de un derecho subjetivo a vivir en un medio ambiente libre de contaminación que consagran algunas normas, como la Constitución Política de Chile (art. $\left.19 \mathrm{~N}^{\circ} 8 \mathrm{CPR}\right)^{66}$.

Otro criterio que utilizan en Chile la doctrina ${ }^{67}$ y jurisprudencia ${ }^{68}$ para distinguir entre derechos subjetivos e intereses legítimos, pone atención a si el legislador utiliza los vocablos lesión o afectación. Si el reclamante afirma la lesión de una posición jurídica subjetiva, en ese caso debe invocar un derecho subjetivo. Pero cuando la ley hace referencia a que el demandante o reclamante debe afirmar que ha sido afectado, en ese caso basta con que invoque un interés, el que debe ser directo. Otros agregan que además de directo debe ser actual ${ }^{69}$. Ese interés es el legítimo.

Con la afectación al sujeto por una decisión administrativa, en ese caso al sujeto le basta invocar un interés legítimo y no necesita afirmar la titularidad de un derecho subjetivo.

En definitiva, se puede concluir que el interés legítimo es una categoría que tiene aún vigencia. Es una categoría conceptualmente válida y una figura presente en el derecho administrativo italiano ${ }^{70}$.

Dicho lo anterior, hay que reiterar que el interés legítimo tiene reconocimiento legislativo y en la doctrina y jurisprudencia chilenas. Tiene reconocimiento legislativo expreso en materias como el derecho laboral y libre competencia y, también, un amplio reconocimiento en la doctrina y jurisprudencia administrativas.

${ }^{65}$ Vid. PIÑAR, Manuel, El derecho a disfrutar del medio ambiente en la jurisprudencia (Granada, Comares, 1998), p. 22.

${ }^{66}$ Vid. Bordalí, Andrés, Tutela jurisdiccional del medio ambiente (Santiago de Chile, Fallos del Mes, 2004), p. 141.

${ }^{67}$ Vid. Bermúdez, Jorge, cit. (n. 13), p. 169.

${ }^{68}$ Vid. Sentencias de la Corte Suprema rol No 219993-2014; rol No 21547 -2014.

${ }^{69}$ Vid. Guerrero, Gonzalo, Legitimación activa de la acción constitucional de nulidad (Santiago de Chile, Librotecnia, 2010), p. 108

${ }^{70}$ Vid. Scoca, Franco Gaetano, Attualità del interesse leggittimo, en Diritto Processuale Amministrativo 29 (2011), 2, p. 417. 
Con el interés legítimo se está frente a una posición jurídica subjetiva de carácter sustancial que se refiere a bienes de la vida que interesan a las personas. Es una figura que convive con el derecho subjetivo, teniendo ambas figuras igual peso ontológico si se permite expresarlo así. Ninguna más o menos que la otra.

Pero más que explicar en qué consiste el interés legítimo, cabe destacar su principal virtud. Y esa virtud es que ha permitido ampliar el acceso a las personas a la Administración y luego a la Justicia Administrativa, para que así puedan impugnar decisiones administrativas que los afectan y que no siempre pueden encasillarse en la figura más estrecha de un derecho subjetivo. Ello ha sido así en materia de concursos y licitaciones públicas, urbanismo y medio ambiente, entre otras materias.

\section{INTERÉS LEGÍTIMO E INTERÉS PARA RECURRIR}

Se acostumbra a señalar que entre los requisitos para poder demandar judicialmente, se debe tener un interés para accionar y estar legitimado activamente. Es decir, cabe distinguir entre tener un interés para demandar y estar legitimado activamente, que consistirá en afirmar ser titular de un derecho subjetivo o interés legítimo.

Se puede decir que el verdadero valor del interés para recurrir o el interés en accionar, demandar o reclamar, términos que consideraré a estos efectos como todos sinónimos, está en la exigencia de evitar que sean sometidas al juez controversias no efectivas, cuestiones abstractas o hipotéticas, donde se le pide al juez opiniones y no decisiones ${ }^{71}$; o bien donde se le pida al juez que falle una cuestión que no reviste ninguna utilidad concreta para el demandante.

El interés en accionar como condición para proponer la demanda ha sido comúnmente puesto en duda, sobre todo si se la considera como algo externo a la acción. Si la ley establece ciertas condiciones para ejercer la acción y éstas se cumplen, surge inmediatamente el interés en accionar. Si no hay interés no hay acción. Entonces exigir un interés en accionar podría parecer ser algo superfluo.

El interés al recurso consiste en la utilidad concreta, aunque sea solo de carácter moral, que la sentencia favorable puede otorgar a la situación jurídica subjetiva de la cual se afirma una lesión. Se trata de una exigencia que se aprecia necesaria para la tutela de situaciones jurídicas subjetivas y, se

${ }^{71}$ Denti, Vittorio, La giustizia civile (Bolonia, Il Mulino, 1989), p. 122. 
ha dicho, exalta el carácter subjetivo de la jurisdicción administrativa. Solo el sujeto que tiene un interés en el resultado del proceso puede demandar ${ }^{72}$.

El interés al recurso es un interés a una sentencia jurisdiccional favorable y concretamente útil. Y si se lo concibe así, se debe señalar que interés al recurso e interés legítimo son dos cosas bien diversas. El interés legítimo como posición jurídica sustancial del sujeto pertenece al patrimonio jurídico del sujeto mientras que el interés al recurso se refiere a la eficiencia del proceso judicial ${ }^{73}$.

En resumen, se trata de un interés procesal en un caso (interés al recurso) y en el otro de un interés material (interés legítimo).

Ese interés al recurso debe ser personal, esto es debe pertenecer a la esfera jurídica del recurrente y no de un tercero. Debe ser además directo, en el sentido que el efecto lesivo deriva inmediatamente de la providencia impugnada. Debe ser además actual, esto es, la lesión ocasionada al sujeto debe existir desde el momento en que se interpone la demanda o reclamación y debe permanecer hasta la decisión sobre el mérito de la pretensión ${ }^{74}$.

En el interés a recurrir todo gira en torno a la utilidad que puede tener la sentencia judicial para el reclamante.

Pero no se puede negar que las características de ambos intereses (interés a recurrir e interés legítimo) suelen solaparse y confundirse. Cuando se dice que el interés debe ser personal, ello puede ser atribuible como característica tanto del interés legítimo como del interés a recurrir. Y algo similar ocurre con la característica que debe ser directo. Si el interés legítimo se lo relaciona con al accionar de la Administración, se puede decir que el interés legítimo debe ser directo, pues la lesión del mismo debe derivar inmediatamente de la decisión impugnada o en aquellos juicios donde no se impugnan actos administrativos, del comportamiento objetado.

Por ello solo el requisito de la actualidad parece ser que puede ser predicado del interés al recurso, ya que solo él puede formar parte del juicio probabilístico futuro acerca de si la utilidad subsiste al momento de interponer la demanda y, también, al momento de dictarse sentencia definitiva.

Para aportar a la claridad, se debe señalar que para poder demandar, el sujeto debe estar legitimado activamente. Lo estará si invoca un derecho subjetivo o un interés legítimo como posiciones jurídicas sustanciales. Ese interés legítimo se caracteriza porque debe ser personal y directo. Cuando

${ }^{72}$ Vid. Follieri, Enrico, I presupposti e le condizioni dell'azione, en Scoca, F. G. (ed.), Giustizia Amministrativa (6º edición, Turín, Giappichelli, 2014), p. 289.

${ }^{73}$ Vid. Spampinato, Biagio, cit. (n. 36), p. 76.

${ }^{74}$ Figuera, Giovanni, Appunti in tema di interesse e legittimazione al ricorso e brevi note sul ricorso principale e ricorso incidentale, en Diritto Procesuale Amministrativo 26 (2008), 4, p. 1084. 
ese interés legítimo recae sobre bienes colectivos como el medio ambiente, pasa a tener la calidad de colectivo, lo que implica que su uso y disfrute sigue siendo atribuible al sujeto, pero ya no es exclusivo ni excluyente del uso y disfrute por otros sujetos ${ }^{75}$.

Pero el sujeto además deberá tener un interés para demandar o recurrir, que debe ser actual. Se trata de un interés procesal que tiene que ver con la eficacia del proceso. Como tal, tiene una vinculación directa con el principio de economía procesal. Si el acto que se impugnó no existe o se corrige al momento en que se presenta la demanda, durante el procedimiento o justo antes de dictarse sentencia definitiva, no es necesario tramitar el proceso o dictarse sentencia definitiva. Y en todo caso, si se llega a dictar sentencia definitiva, debe rechazarse la demanda. Ese proceso o esa sentencia ya no son útiles y, por tanto, no se justifica tramitar un proceso o dictar una sentencia que no tendrá efectos útiles.

\section{Conclusiones}

La tutela jurisdiccional que debe recibir el particular cuando ha sido afectado por la Administración del Estado, debe reparar el daño injusto que se le ha causado o bien se le debe conceder la ventaja o utilidad de la que se le había injustamente privado.

Esa idea de daño causado o de ventaja o utilidad de que ha sido privado el sujeto injustamente, corresponde a la expresión "lesionada en sus derechos" de que habla el artículo 38 inciso $2^{\circ} \mathrm{CPR}$.

Y esa idea de daño causado o de ventaja o utilidad de que ha sido privado el sujeto injustamente, también se corresponde con las expresiones que usa la Ley de Tribunales Ambientales en su artículo 18, como "causar perjuicio", "directamente afectadas", "lesionada en sus derechos", etc.

En la base de ese daño causado o ventaja o utilidad privadas injustamente, puede haber la afectación de un derecho subjetivo, o bien, de un interés legítimo.

Lo anterior quiere decir que estará legitimado activamente para interponer una reclamación ambiental quien afirme ser titular de un derecho subjetivo o bien de un interés legítimo. Ambas posiciones jurídicas subjetivas deben ser atribuidas al sujeto que reclama, ya sea en una hipótesis de exclusividad y exclusión en su uso y disfrute (derecho o interés individual) o bien sin que el goce sea exclusivo ni excluyente para el sujeto (derecho o interés colectivo).

${ }^{75}$ Vid. Bordalí, Andrés, cit. (n. 66), pp. 81 ss. 
En todos esos casos se trata de posiciones jurídicas subjetivas sustanciales referidas a distintos bienes de la vida que reconoce el ordenamiento jurídico.

Pero, además de ese derecho o interés legítimo que se encuentra en la base de la reclamación y en el requisito de la legitimación activa, debe existir una concreta utilidad en el proceso que se desarrollará y en la sentencia definitiva que se dictará a futuro. El proceso y la sentencia deben ser útiles para el actor. Por ello se dice que debe concurrir otra exigencia para el demandante; un interés no sustancial sino procesal; un interés el recurso o interés para accionar.

Por ello, cuando se dice que el interés debe ser actual, no se debe hacer referencia al interés legítimo sino al interés para recurrir, que tiene una naturaleza procesal y no material.

La concepción del interés legítimo esbozada en este trabajo es coherente con un sistema jurídico que pone a la persona como centro de todas sus regulaciones. Por tanto, una Administración puede actuar para la búsqueda y consecución de fines públicos legítimos, pero debe hacerlo respetando los derechos subjetivos e intereses legítimos de los privados. $Y$ si no lo hace de ese modo, los sujetos afectados podrán reclamar ante la Justicia Administrativa para que ésta de amparo a sus derechos subjetivos o intereses legítimos afectados por la Administración.

\section{BiBLIOGRAFÍA}

Benvenuti, Luigi, Diritto e amministrazione. Itinerari di storia del pensiero (Turín, Giappichelli, 2011).

Bermúdez, Jorge, La legitimación activa en el contencioso ambiental, en FerRAda, Juan Carlos - Bermúdez, Jorge - Pinilla, Francisco (coords.), La nueva justicia ambiental (Santiago de Chile, Thomson Reuters, 2015).

Bordalí, Andrés, Tutela jurisdiccional del medio ambiente (Santiago de Chile, Fallos del Mes, 2004).

Bordalí, Andrés - HunTer, Iván, Contencioso administrativo ambiental (Santiago de Chile, Librotecnia, 2017).

Casarino, Mario, Manual de Derecho Procesal. Derecho Procesal Civil (Santiago, Editorial Jurídica de Chile, 1994), III.

Cordero, Eduardo, La legitimación activa en el proceso contencioso - administrativo, en Ferrada, Juan Carlos (coord.), La justicia administrativa (Santiago, Editorial Jurídica de Chile, 2005).

Denti, Vittorio, La giustizia civile (Bolonia, Il Mulino, 1989).

Fazzalari, Elio, Processo e giurisdizione, en Rivista di Diritto Processuale 48 (1993, II serie), 1.

FERRADA, Juan Carlos, El sistema de justicia administrativa chileno: revisión de la legalidad de actos administrativos o protección de derechos y/o intereses en Revista de Derecho (Valdivia) 25 (2012), 1. 
Ferrajoli, Luigi, Principia iuris. Teoria del diritto e della democrazia,. 1. Teoria del diritto (Roma, Laterza, 2007).

FIguera, Giovanni, Appunti in tema di interesse e legittimazione al ricorso e brevi note sul ricorso principale e ricorso incidentale en Diritto Procesuale Amministrativo 27 (2008), 4.

Follieri, Enrico, I presupposti e le condizioni dell'azione, en SCOCA, F. G. (ed.), Giustizia Amministrativa (6º edición, Turín, Giappichelli, 2014).

Goldschmidt, James, Teoría general del proceso (Barcelona, Labor, 1936).

GuERrERo, Gonzalo, Legitimación activa de la acción constitucional de nulidad (Santiago de Chile, Librotecnia, 2010).

IannotTa, Lucio, L'interesse legittimo nell'ordinamento republicano, en Diritto Processuale Amministrativo (2007), 4.

Lombardi, Roberta, Le azioni collettive, en Scoca, Franco Gaetano (ed.), Giustizia Amministrativa (6o edición, Turín, Giappichelli, 2014).

Mazzamuto, Marco, A cosa serve l'interesse legittimo?, en Diritto Processuale Amministrativo 30 (2012).

Montero, Juan, La legitimación en el proceso civil (intento de aclarar un concepto que resulta más confuso cuando más se escribe de él) (Madrid, Civitas, 1994).

Nigro, Mario, Giustizia amministrativa (6º edición, Bolonia, Il Mulino, 2002).

Nivarra, Luca - Ricciuto, Vincenzo - Sconamiglio, Claudio, Istituzioni di Diritto Privato (Turín, Giappichelli, 2016).

PINÁAR, Manuel, El derecho a disfrutar del medio ambiente en la jurisprudencia (Granada, Comares, 1998).

Porro, Angelo, Le origini del sistema di giustizia amministrativa in Italia. Riflessioni e documenti (Milán, Librerie Cuem, 1995).

Ricci, Gian Franco, Principi di diritto processuale generale (3º edición, Turín, Giappichelli, 2001).

Romero, Alejandro, Curso de Derecho Procesal Civil. La acción y la protección de los derechos (Santiago, Editorial Jurídica de Chile, 2006), I.

Scoca, Franco Gaetano, Attualità del interesse leggittimo, en Diritto Processuale Amministrativo 29 (2011), 2.

Scoca, Franco Gaetano, La genesi del sistema delle tutele nei confronti della pubblica amministrazione, en ScOCA, F. G. (ed.), Giustizia amministrativa (6º edición, Turín, Giappichelli, 2014).

Spampinato, Biagio, L'interesse a ricorrere nel processo amministrativo (Milán, Giuffrè, 2004).

TravI, Aldo, Lezioni di giustizia amministrativa, décima segunda edición (Turín, Giappichelli, 2016).

Verde, Giovanni, Ma che cos'è questa giustizia amministrativa, en Diritto Processuale Amministrativo (1993), 4.

ZITо, Alberto, L'ambito della giurisdizione del giudice amministrativo, en SCOCA, Franco Gaetano (ed.), Giustizia amministrativa (6º edición, Turín, Giappichelli, 2014). 